\title{
REGULAR SCREENING OF ANTI-HBS ANTIBODY TITRE AND THE NEED FOR BOOSTERS AMONG HEALTH CARE WORKERS IN A TERTIARY CARE HOSPITAL IN PATNA
}

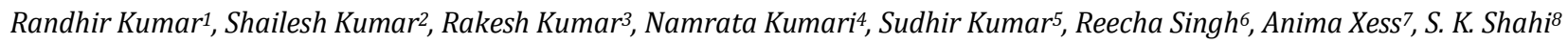

${ }^{1}$ Senior Resident, Department of Microbiology, Indira Gandhi Institute of Medical Sciences, Patna.

${ }^{2}$ Additional Professor, Department of Microbiology, Indira Gandhi Institute of Medical Sciences, Patna.

${ }^{3}$ Assistant Professor, Department of Microbiology, Indira Gandhi Institute of Medical Sciences, Patna.

${ }^{4}$ Professor, Department of Microbiology, Indira Gandhi Institute of Medical Sciences, Patna.

${ }^{5}$ Additional Professor, Department of Medicine, Indira Gandhi Institute of Medical Sciences, Patna.

${ }^{6}$ Associate Professor, Department of Pathology, Indira Gandhi Institute of Medical Sciences, Patna.

7Professor, Department of Microbiology, Indira Gandhi Institute of Medical Sciences, Patna.

sProfessor, Department of Microbiology, Indira Gandhi Institute of Medical Sciences, Patna.

\section{BACKGROUND}

ABSTRACT

Health care workers because of their contact with patients and with potentially infectious materials have risk of exposure to infectious diseases, some of which are preventable by vaccination. The goal of immunisation for appropriate intervention in the health workforce is critical to prevent and control infections. Antibodies-HBs indicate presence of immunological memory. Their persistent negativity indicates the need to complete the vaccination series with two additional doses followed by a new serological testing after one month.

The objective of this study is to evaluate anti-HBs antibody titre among vaccinated health care workers and to determine awareness level of antibody titre among HCW at IGIMS, Patna.

\section{MATERIALS AND METHODS}

A prospective study was carried out. A total of 92 nursing staffs, laboratory technicians, paramedical staffs, doctors and students were tested to evaluate their immunity toward hepatitis B. The anti-HBs antibody levels were detected using the anti-HBs ELISA test (enzyme immunoassay diagnostic kit for in vitro qualitative detection of antibody to hepatitis B surface antigen in human serum or plasma). Inadequate immune response to $\mathrm{HBV}$ vaccination was considered if quantitative anti-HBs level was $<10.0 \mathrm{mIU} / \mathrm{mL}$ according to the Centre for Disease Control (CDC).

\section{RESULTS}

Of the 92 vaccinated health care workers, anti-HBs antibody titre was noted and only 47 (51.08\%) had protective titre.

\section{CONCLUSION}

Our study represents one of the first experience in IGIMS regarding the level of anti-HBs antibody titre in health care workers. The low titre emphasises the need for monitoring vaccination status among health care workers.

\section{KEYWORDS}

Antibodies, Hepatitis B Virus, Immunisation.

HOW TO CITE THIS ARTICLE: Kumar R, Kumar S, Kumar R, et al. Regular screening of anti-HBs antibody titre and the need for boosters among health care workers in a tertiary care hospital in Patna. J. Evolution Med. Dent. Sci. 2018;7(04):504-506, D0I: $10.14260 /$ jemds/2018/112

\section{BACKGROUND}

Health care workers (HCW), because of their contact with patients and with potentially infectious materials have risk of exposure to infectious diseases. The goal of immunisation is to prevent and control infections. Antibodies-HBs indicate presence of immunological memory. Their persistent negativity indicates the need to complete the vaccination series with two additional doses followed by a new serological testing after one month. With 50 million cases,

'Financial or Other Competing Interest': None.

Submission 15-12-2017, Peer Review 08-01-2018,

Acceptance 13-01-2018, Published 22-01-2018.

Corresponding Author:

Dr. Shailesh Kumar.

Quarter No. E2/2,

Indira Gandhi Institute of Medical Sciences,

Patna-14.

E-mail: shaileshgar@yahoo.com

DOI: $10.14260 /$ jemds $/ 2018 / 112$

(c) (i) (3) $\Theta$
India is also the second largest global pool of chronic HBV infections. ${ }^{1}$ It has been reported that about $10 \%$ of the health care workers (HCWs) in India have acquired HBV infection. ${ }^{2}$ The risk for developing serologic evidence of HBV infection was $37 \%$ to $62 \%$ if the blood was positive for both HBsAg and hepatitis B e-antigen, and $23 \%$ to $37 \%$ if the blood was positive for HBsAg and negative for hepatitis B e-antigen. ${ }^{3}$ HCWs exposed to needle stick injuries (NSIs), blood containing HBV or both are at risk for developing clinical hepatitis.3,4 Low vaccination rates among HCWs have been reported in Nigeria, South Africa and India. ${ }^{5-7}$

\section{Objective}

To evaluate anti-HBs antibody titre among vaccinated health care workers and to determine awareness level of antibody titre among HCW at IGIMS, Patna.

\section{MATERIALS AND METHODS}

The study was conducted at IGIMS, Patna. 


\section{Study Design and Sample Size}

This was a questionnaire-based, cross-sectional study conducted with HCWs. Health care workers (whose activities involved contact with patient's blood or other body fluids while providing care) such as doctors (including postgraduates and interns), nurses, lab technicians and paramedical staffs were considered for the study.

Pretesting appropriate questionnaire was prepared to collect information regarding occupation, Hepatitis B vaccination status and details about doses.

\section{Sample Collection}

Four millilitres of whole blood were collected from each respondent. Then the sera were separated and frozen at $-20^{\circ}$ C until tested. The anti-HBs antibody levels were detected using the HBsAg ELISA commercially available kit (Bioneovan) (enzyme immunoassay diagnostic kit for in vitro qualitative detection of antibody to hepatitis B surface antigen in human serum or plasma). Inadequate immune response to $\mathrm{HBV}$ vaccination was considered if quantitative anti-HBs level was < 2.088 (OD-0.104)

\section{Data Collection}

Permission was obtained from the Institutional Ethics Committee to conduct the study. It was made clear that the participation was voluntary. The completed forms were collected and the data analysed.

\section{RESULTS}

92 HCWs participated. Of the participants, 70 (76\%) were females and 22 (24\%) were males. The distribution according to designation of the participants was as follows: 21 (23\%) doctors, 26 (28\%) nurses and 45 (49\%) laboratory technicians and paramedical staffs (Table 1). Of the 92 vaccinated health care workers, anti-HBs antibody titre was noted and only $47(51.08 \%)$ had protective titre. In all 4 $(4.3 \%)$ of 92 HCWs had taken at least 1 dose of vaccine, 23 (25\%) had taken 2 doses of vaccine, $42(45.6 \%)$ had taken 3 doses of vaccine, but no booster. Complete primary vaccination and booster was taken by 20 (21.8\%). 3 (3.3\%) did not remember the vaccination dose (Table 2). Correlation of dose schedule with antibody titre is shown in (Fig. 1). Sex distribution of protected antibody titre among health care workers is illustrated in (Table 3, Fig. 2 and 3).

\begin{tabular}{|c|c|c|c|}
\hline Occupation & Protected & Not Protected & Total N (\%) \\
\hline Doctors & 17 & 4 & $21(23 \%)$ \\
\hline Nurses & 15 & 11 & $26(28 \%)$ \\
\hline $\begin{array}{c}\text { Lab Tech. } \\
\text { and } \\
\begin{array}{c}\text { Paramedical } \\
\text { Staff }\end{array}\end{array}$ & 22 & 23 & $45(49 \%)$ \\
\hline \begin{tabular}{|c|} 
Table 1. Distribution of Protected Antibody Titre among \\
Health Care Workers
\end{tabular} \\
\hline
\end{tabular}

\begin{tabular}{|c|c|c|c|}
\hline $\begin{array}{c}\text { No. of Dose of } \\
\text { Vaccination in } \\
\text { Primary Series and } \\
\text { Booster }\end{array}$ & n (\%) & Protected & $\begin{array}{c}\text { Not } \\
\text { Protected }\end{array}$ \\
\hline 1 dose & $4(4.3 \%)$ & $0(0 \%)$ & $4(4.3 \%)$ \\
\hline 2 doses & $23(25 \%)$ & $13(14 \%)$ & $10(11 \%)$ \\
\hline $\begin{array}{c}3 \text { doses without } \\
\text { booster }\end{array}$ & $42(45.6 \%)$ & $23(25 \%)$ & $19(20.6 \%)$ \\
\hline
\end{tabular}

\begin{tabular}{|c|c|c|c|}
\hline 3 doses with booster & $20(21.8 \%)$ & $16(17.4 \%)$ & $4(4.3 \%)$ \\
\hline Not remembered & $3(3.3 \%)$ & $2(2.2 \%)$ & $1(1.1 \%)$ \\
\hline & & 54 & 38 \\
\hline \multicolumn{2}{|c|}{ Table 2. Correlation of Dose Schedule with Antibody Titre } \\
\hline
\end{tabular}
$(n=92)$

\begin{tabular}{|c|c|c|c|}
\hline Sex & Protected & Not Protected & Total \\
\hline Male & 11 & 11 & 22 \\
\hline Female & 43 & 27 & 70 \\
\hline \multicolumn{4}{|c|}{ Table 3. Sex Distribution of Protected Antibody Titre } \\
among Health Care Workers \\
\hline
\end{tabular}

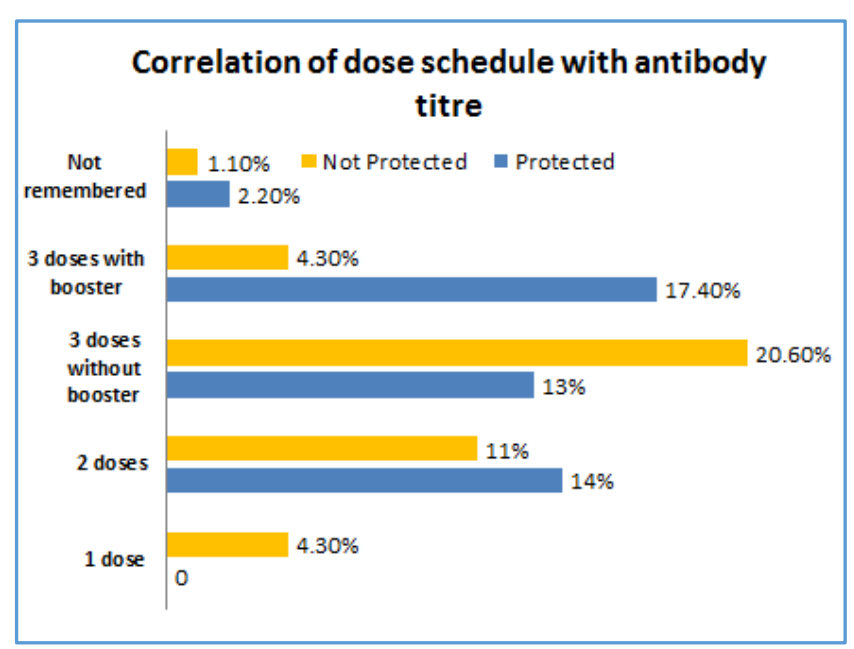

Figure 1

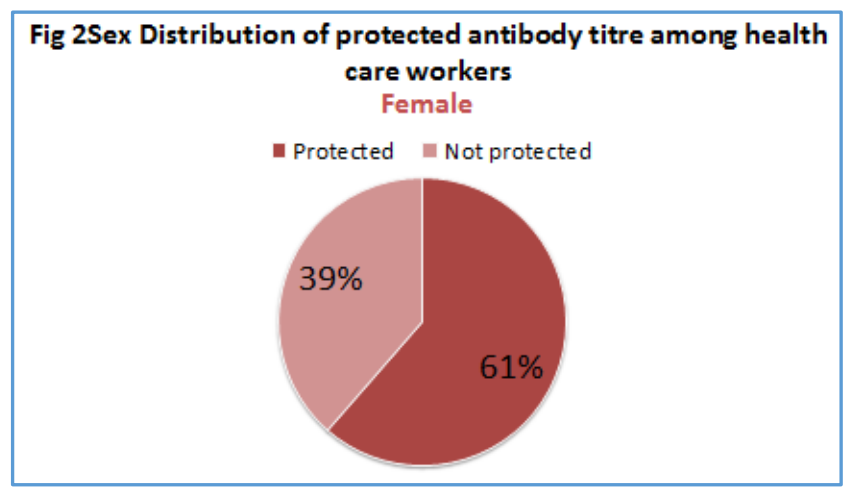

Figure 2

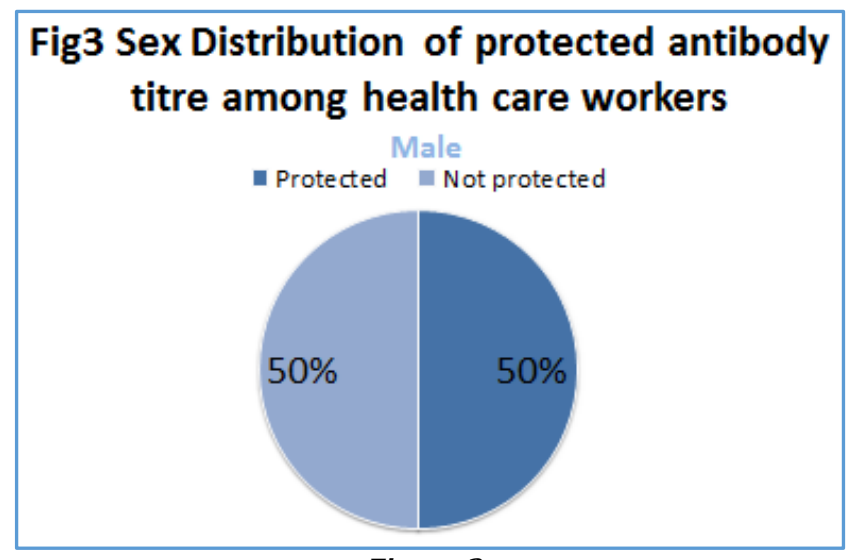

Figure 3

\section{DISCUSSION}

Vaccination against Hepatitis B is must for all the HCWs. WHO has estimated only $18 \%$ - $39 \%$ vaccination coverage of 
Hepatitis B among HCWs of low and middle-income countries compared to $67 \%-79 \%$ in high income countries. HBV vaccination is now part of national routine immunisation program for children in India. In a study done by Harsha $\mathrm{K}$ et al, 8 nearly all (93.8\%) of the HCWs surveyed had taken 1 dose of hepatitis B vaccine, only $57.1 \%$ completed the primary series of 3 doses and only $26.4 \%$ had taken 1 or more booster doses. This is in agreement with our study- $45.6 \%$ completed the primary series of 3 doses and only $22 \%$ ) had taken the booster. In a study done by Madhumita $\mathrm{D}$ et $\mathrm{al}^{9}$ at Lady Hardinge College, Delhi, (67\%) HCWs had a protective level of anti-HbsAb level which is similar to our study (59\%). HCWs had a protective titre. There is sufficient evidence that the levels of anti-HBs antibody are related to the number of doses of vaccine administered. Jha AK et al ${ }^{10}$ (Delhi, 2012) and Sukriti et al7 (India, 2008) also reported similar findings, i.e. the percentage of HCWs who had protective level of antiHBsAb titre after complete vaccination was $73.5 \%$ and $82.2 \%$ respectively. This is in accordance with our study which shows $80 \%$ of participants with complete vaccination with protective titre. HBV vaccination in HCWs including medical students and trainees in India is recommended, but not strictly enforced or mandatory like in United Kingdom (UK) and Spain. ${ }^{11,12}$

"No responder" subjects after a vaccine series may be administered up to 3 additional doses (at 0, 1 and 6 months) for protection. Recently, for these subjects a new vaccination schedule has been proposed, which is 2 doses simultaneously in deltoid muscles followed by a similar dose after 2 months and serological testing at interval of two months. Limitations of our study are less participants, low awareness among HCWs and cost of kit.

\section{CONCLUSION}

Our study at IGIMS shows the low level of vaccination awareness among HCWs. Protective titre was seen more with complete vaccination. This study highlights the need to improve the vaccination coverage to protect the workers from acquiring hepatitis $\mathrm{B}$ infection. Refresher training programme should also be conducted to update the knowledge of HCWs on regular basis.

\section{REFERENCES}

[1] World Health Organization. Hepatitis B fact sheet-July 2012.

[2] Elavia AJ, Banker DD. Hepatitis B virus infection in hospital personnel. Natl Med J India 1992;5(6):265-8.
[3] Werner BG, Grady GF. Accidental hepatitis-B-surfaceantigen-positive inoculations: use of e antigen to estimate infectivity. Ann Intern Med 1982;97(3):3679.

[4] Lauer JL, van Drunen NA, Washburn JW, et al. Transmission of hepatitis B virus in clinical laboratory areas. J Infect Dis 1979;140(4):513-6.

[5] Kesieme EB, Uwakwe K, Irekpita E, et al. Knowledge of hepatitis $B$ vaccine among operating room personnel in Nigeria and their vaccination status. Article ID 157089, Hepat Res Treat 2011;2011: p. 5.

[6] Talaat M, Kandeel A, El Shoubary W, et al. Occupational exposure to needlestick injuries and hepatitis $\mathrm{B}$ vaccination coverage among health care workers in Egypt. Am J Infect Control 2003;31(8):46974.

[7] Sukriti, Pati NT, Sethi A, et al. Low levels of awareness, vaccine coverage and the need for boosters among healthcare workers in tertiary care hospitals in India. J Gastroenterol Hepatol 2008;23(11):1710-5.

[8] Kumar HNH, Nambiar RP, Mohapatra S, et al. A crosssectional study on Hepatitis B vaccination status and post-exposure prophylaxis practices among health care workers in teaching hospitals of Mangalore. Annals of Global Health 2015;81(5):664-8.

[9] Debbarma M, Gogoi S, Jais M, et al. Awareness and status of Hepatitis B vaccination among health care workers in a tertiary care centre of North India. British Journal of Medical and Health Research 2016;3(6)84-91.

[10] Jha AK, Chadha S, Bhalla P, et al. Hepatitis B infection in microbiology laboratory workers: prevalence, vaccination and immunity status. Article ID 520362, Hepat Res Treat 2012;2012: p. 5.

[11] Mast EE, Weinbaum CM, Fiore AE, et al. Centers for Disease Control and Prevention (CDC). A comprehensive immunization strategy to eliminate transmission of Hepatitis B virus infection in the United States: recommendations of the Advisory Committee on Immunization Practices (ACIP) Part II: Immunization of Adults. MMWR Recomm Rep 2006;55(16):1-25. www.bjmhr.com

[12] De Schryver A, Claesen B, Meheus A, et al. European survey of Hepatitis B vaccination policies for healthcare workers. Eur J Public Health 2011;21(3):338-43. 